\title{
Near-Death Experiences and Satisfaction with Life
}

\author{
Bruce Greyson, M.D. \\ University of Connecticut
}

\begin{abstract}
$A B S T R A C T$ : Near-death experiences (NDEs) are reported to produce positive changes in attitudes, beliefs, and values that might be expected to enhance the experiencers' satisfaction with life. Global satisfaction with life was examined among a sample of self-selected near-death experiencers, individuals who had come close to death without an NDE, and individuals who had never been close to death. NDErs' life satisfaction was not different from that of the two control groups, suggesting that problems readjusting to life after an NDE may offset any enhanced life satisfaction that may result from positive personality transformations.
\end{abstract}

The near-death experience (NDE) is a profound subjective event with transcendental or mystical elements reported by about onethird of people who come close to death (Greyson, 1994). While there is little consensus among researchers as to the causes and ultimate meaning of the NDE, there is considerable evidence of a consistent pattern of change in beliefs, attitudes, and values following the experience.

Commonly described aftereffects of the NDE include a renewed sense of purpose in life, greater appreciation of life, greater self-confidence and self-esteem, a heightened sense of spirituality and of altruism, shift of emotional investment from material goals and competition to interpersonal relationships and helping others, and, most consistently, decreased fear of death (Bauer, 1985; Flynn, 1982; Greyson, 1983a; Noyes, 1980; Ring, 1984; Sabom, 1982). At least

Bruce Greyson, M.D., is Professor of Psychiatry at the University of Connecticut School of Medicine. Reprint requests should be addressed to Dr. Greyson at the Department of Psychiatry, University of Connecticut Health Center, Farmington, CT 06030-6410. 
some of these aftereffects might be expected to enhance the experiencers' satisfaction with life.

Furthermore, most near-death experiencers interpret their experience as an encounter with the divine (Ring, 1984). Divine interaction is thought to enhance well-being in a variety of ways: it provides a resource for resolving problems, reshapes the experiencer's sense of self as empowered by divine support, and expands the experiencer's sense of the coherence, comprehensibility, and meaningfulness of life (Pollner, 1989). Melvin Pollner (1989) proposed that divine relations, such as those reported by many NDErs, foster a positive framing of life events in general and an experience of living in the world as essentially good.

On the other hand, there is a sizable literature attesting to significant interpersonal and intrapsychic problems readjusting to life after an NDE (Atwater, 1988; Furn, 1987; Greyson and Harris, 1987; Insinger, 1991). In addition to whatever disability may result from the causes of their encounters with death, experiencers may be left with considerable distress secondary to the NDE itself or to difficulty integrating it into their lives.

Melodie Olson and Peggy Dulaney (1993) studied the relationship between near-death experiences and life satisfaction in the elderly. They solicited volunteers from senior citizens' groups meeting for social reasons; of their 146 volunteers, 46 reported a close brush with death, 15 of those reported some kind of unusual experience during that near-death event, and 12 of those 15 were available to be interviewed. Of those 12 presumptive near-death experiencers, five were judged to have had a near-death experience by virtue of having scored 7 or greater on the NDE Scale (Greyson, 1983b), and four others reported some characteristics of a near-death experience.

As a measure of life satisfaction, Olson and Dulaney used a revised version of the Life Satisfaction Index-A (LSI-A), an 18-item self-report questionnaire with several items focusing specifically on old age (Neugarten, Havighurst, and Tobin, 1961; Adams, 1969) that explores constructs such as congruence between achieved and desired goals, zest for life, and mood. Comparison of LSI-A scores between those who had had NDEs and those who had not showed no significant differences. However, Olson and Dulaney expressed little confidence in those results because of the small number of NDErs in their sample.

The present study was an exploration of satisfaction with life among a larger sample of near-death experiencers of all ages. I con- 
trasted scores on a global life satisfaction scale among NDErs to scores among two control groups: a sample of individuals who had come close to death without experiencing an NDE and a sample of individuals who had never been close to death.

\section{Method}

\section{Instruments}

Subjects were mailed questionnaires, which they completed and returned identified only by anonymous subject number. All subjects completed the Satisfaction With Life Scale (Diener, Emmons, Larsen, and Griffin, 1985), a 5-item Likert-type questionnaire designed to measure global life satisfaction. Subjects rate each item, such as "So far I have gotten the important things I want in life," from 1 (strongly disagree) to 7 (strongly agree). The Satisfaction With Life Scale has internal consistency and temporal reliability, is suitable for all adult age groups, is positively correlated with other measures of subjective well-being, and is free of social desirability response set.

In addition, those subjects who reported having been close to death at some point in their lives completed the NDE Scale (Greyson, 1983b), a 16-item multiple-choice questionnaire designed to measure the occurrence and depth of a near-death experience and its cognitive, affective, paranormal, and transcendental components. The NDE Scale has documented reliability and validity and significantly differentiates NDEs from other close brushes with death (Greyson, 1990). For research purposes, a score of 7 or more points (out of a possible 32) on the NDE Scale is recommended as the criterion for labeling an experience an NDE (Greyson, 1983b). Subscale scores also permit an NDE to be categorized as predominantly cognitive, affective, paranormal, or transcendental (Greyson, 1985, 1990).

\section{Subjects}

Subjects were recruited through advertisements in the newsletter of the International Association for Near-Death Studies, an international organization founded to promote research into NDEs. The study sample included 275 subjects: 126 individuals reported having had NDEs and described experiences that scored 7 or greater on the 
NDE Scale, 40 individuals reported having had a close brush with death without NDEs and described experiences that scored less than 7 on the NDE Scale, and 109 individuals denied ever having been close to death.

\section{Results}

The mean score of all 275 subjects on the Satisfaction With Life Scale was 22.89 (S.D. $=6.88$ ), and the scores ranged from 5 to 35 . The mean score for the 121 males in this sample was 22.35 (S.D = 6.57), and for the 154 females, 22.91 (S.D. = 7.12). This difference between genders was not significant ( $\mathrm{df}=1, \mathrm{t}=0.70$ ).

The mean age of this sample was 49.5 years (S.D. $=13.6$ ). For the 166 subjects who had come close to death, the mean age at the time of that brush with death was 31.9 years (S.D. $=15.6$ ), and the mean time elapsed since that brush with death was 19.1 years (S.D. = 15.2). Scores on the Satisfaction With Life Scale were not significantly associated with age at the time of the study $(r=.07)$, with age at the time of the close brush with death $(r=-.07)$, or with time elapsed since that brush with death $(r=.11)$.

The mean score for the 126 subjects who had had NDEs was 23.16 (S.D. = 7.12); for the 40 subjects who had come close to death without NDEs, 23.13 (S.D. = 6.27); and for the 109 subjects who have never come close to death, 22.48 (S.D. = 6.40). Mean scores did not differ significantly among these three groups.

For the 166 subjects who had come close to death, the mean score on the NDE Scale was 13.02 (S.D. = 8.48). Mean scores for this sample on the subscales were 2.93 (S.D. $=2.29$ ) for the cognitive component, 4.39 (S.D. $=2.97$ ) for the affective component, 2.59 (S.D. $=$ 2.14) for the paranormal component, and 3.12 (S.D. $=2.76$ ) for the transcendental component. Scores on the Satisfaction With Life Scale were not significantly associated with scores on the NDE Scale ( $\mathrm{r}=$ .09 ), nor with scores on any of the component subscales (cognitive, $\mathrm{r}=.11$; affective, $\mathrm{r}=.16$; paranormal, $\mathrm{r}=.02$; and transcendental, $r=.00$ ).

Among the 123 subjects whose NDEs could be classified according to type, the mean score on the Satisfaction With Life Scale was 23.94 (S.D. $=7.56$ ) for the 49 subjects reporting cognitive NDEs, 21.42 (S.D. $=5.48$ ) for the 38 subjects reporting affective NDEs, 20.25 (S.D. = 10.08) for the four subjects reporting paranormal NDEs, and 22.19 
(S.D. $=6.78)$ for the 32 subjects reporting transcendental NDEs. Mean scores did not differ significantly among these four groups of near-death experiencers $(\mathrm{df}=3,119 ; \mathrm{F}=1.24)$.

\section{Discussion}

These data suggest that, despite consistent evidence of positive personality transformations following NDEs and the sense of interaction with the divine, experiencers do not report greater satisfaction with life than do control populations, nor is satisfaction with life associated with depth or type of NDE. Though these results may be counterintuitive, they support and expand the findings of Olson and Dulaney, who found no enhanced life satisfaction among a small sample of elderly NDErs. Previous studies have documented significant problems readjusting to life following an NDE (Atwater, 1988; Furn, 1987; Greyson and Harris, 1987; Insinger, 1991). It may be that for many near-death experiencers, those adjustment problems are sufficient to offset any influence of positive changes in attitudes, beliefs, and values on enhancing global satisfaction with life.

\section{References}

Adams, D. L. (1969). Analysis of the Life Satisfaction Index. Journal of Gerontology, $24,470-474$.

Atwater, P. M. H. (1988). Coming back to life: The after-effects of the near-death experience. New York, NY: Dodd, Mead.

Bauer, M. (1985). Near-death experiences and attitude change. Anabiosis: The Journal of Near-Death Studies, 5(1), 39-47.

Diener, F., Emmons, R. A., Larson, R. J., and Griffin, S. (1985). The Satisfaction With Life Scale. Journal of Personality Assessment, 49, 71-75.

Flynn, C. P. (1982). Meanings and implications of NDEr transformations: Some preliminary findings and implications. Anabiosis: The Journal of Near-Death Studies, 2, 3-14.

Furn, B. (1987). Adjustment and the near-death experience: A conceptual and therapeutic model. Journal of Near-Death Studies, 6, 4-19.

Greyson, B. (1983a). Near-death experiences and personal values. American Joumal of Psychiatry, 140, 618-620.

Greyson, B. (1983b). The Near-Death Experience Scale: Construction, reliability, and validity. Journal of Nervous and Mental Disease, 171, 369-375.

Greyson, B. (1985). A typology of near-death experiences. American Journal of Psychiatry, 142, 967-969.

Greyson, B. (1990). Near-death encounters with and without near-death experiences: Comparative NDE Scale profiles. Journal of Near-Death Studies, 8, 151-161. 
Greyson, B. (1994). Near-death experiences. In R. Corsini (Ed.), Encyclopedia of psychology, 2nd edition (pp. 460-462). New York, NY: Wiley.

Greyson. B., and Harris, B. (1987). Clinical approaches to the near-death experiencer. Journal of Near-Death Studies, 6, 41-52.

Insinger, M. (1991). The impact of a near-death experience on family relationships. Journal of Near-Death Studies, 9, 141-181.

Neugarten, B. L., Havighurst, R. J., and Tobin, S. S. (1961). Measurement of life satisfaction. Journal of Gerontology, 16, 134-143.

Noyes, R., Jr. (1980). Attitude change following near-death experiences. Psychiatry, 43, 234-242.

Olson, M., and Dulaney, P. (1993). Life satisfaction, life review, and near-death experiences in the elderly. Journal of Holistic Nursing, 11, 368-382.

Pollner, M. (1989). Divine relations, social relations, and well-being. Journal of Health and Social Behavior, 30, 92-104.

Ring, K. (1984). Heading toward omega: In search of the meaning of the near-death experience. New York, NY: Morrow. 